\title{
1990 MRS Fall Meeting Mixes New Science with Traditional Materials
}

\section{Topics Range from Surface Chemistry and Materials Defects to Layered Structures and Buckyballs}
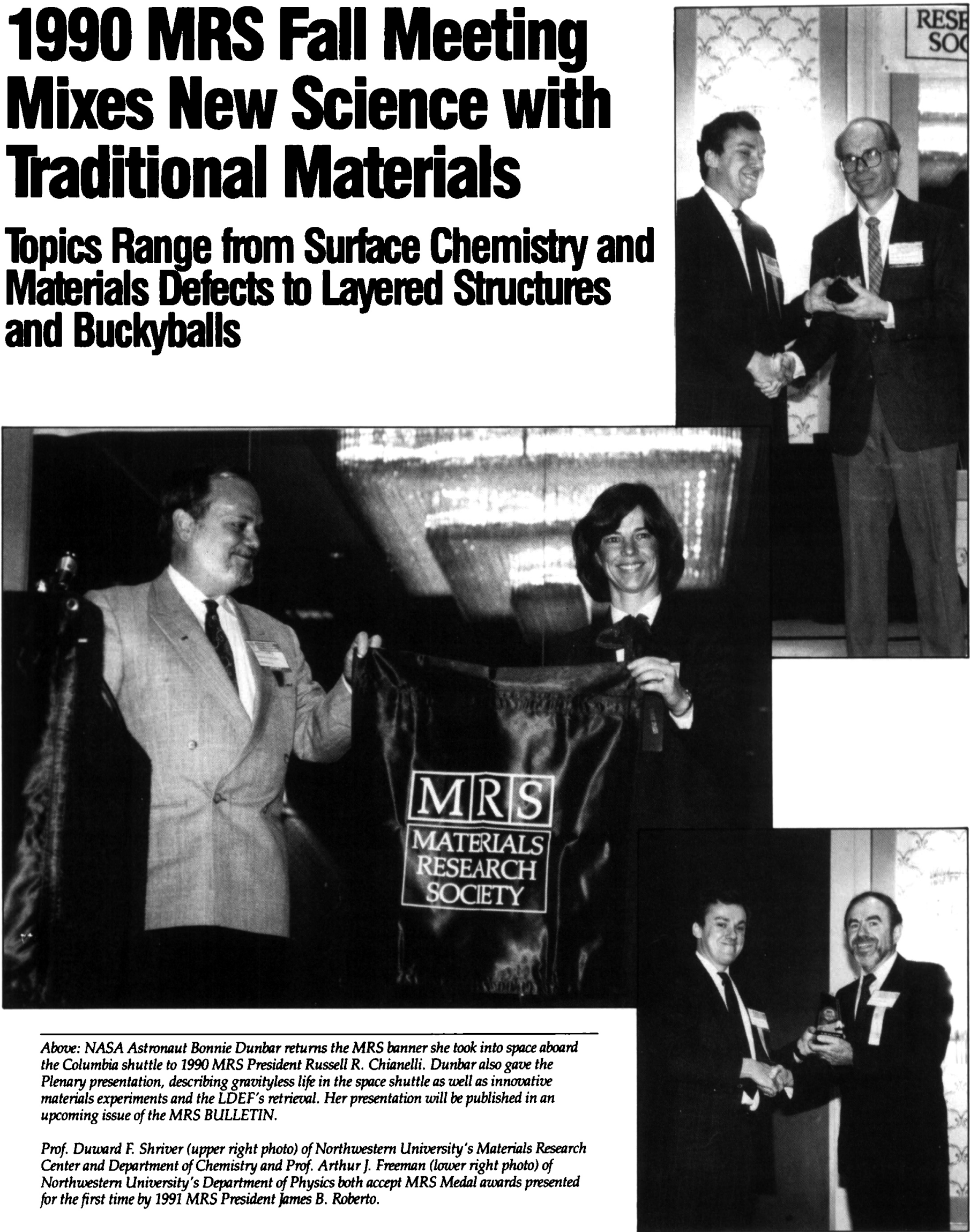
Every MRS meeting brings to life new fields, connects old fields in new ways, and exposes interesting science hidden deep in laboratories for months. The 1990 MRS Fall Meeting, with its 3,762 participants and more papers presented than any previous MRS meeting, supported that tradition.

Robert Hull, AT\&T Bell Laboratories, Gregory J. McCarthy, North Dakota State University, and Frans Spaepen, Harvard University, chaired perhaps the smoothest running meeting to date. Audio visual needs and special requests were satisfied promptly, and new procedures shortened registration lines.

Meeting topics ranged from materials traditionally associated with materials science (metals, ceramics, polymers, and semiconductors) to materials as diverse as apples, protein, and sandpiles. Many of the materials crossed borders: polymers that conduct, liquids that behave like solids when squeezed between smooth surfaces, biological systems that act as polymer factories, and high tech concrete that contains radioactive waste. Even the familiar carbon appeared as neither diamond nor graphite, but as a stable 60 car- bon structure shaped like a soccer ball.

Biology contributed a number of lessons. A session on tomography described how techniques such as Nuclear Magnetic Resonance (NMR), x-ray, and ultrasound can produce three-dimensional images of the insides of materials nondestructively, just like the medical profession does for humans. Well-designed biological systems such as grass, trees, and seeds are often taken for granted. But by studying how these natural systems resist cracking and how they recover from deformation, scientists are learning more about toughness and fracture. Other researchers examined how silkworms and spiders make light, strong, tough, and nearly defect-free fibers through room temperature processing of aqueous solutions, something not yet accomplished by scientists. Protein such as bacteriorhodopsin has also entered the materials world, as a light sensing component in molecular electronic devices.

In her Plenary presentation, NASA astronaut Bonnie Dunbar showed movies of life without gravity in the space shuttle, dramatic views of earth, and innovative materials experiments, which elicited at least one comment of "Where do I sign up?" Dunbar's presentation will appear in a future issue of the MRS BULLETIN. The MRS Continuing Education Committee took the opportunity to invite a number of elementary, junior high, and high school students in Boston to meet with Dunbar before attending the talk to learn firsthand about the potential of science in space, gain some perspective on the Earth, and learn about the effects of gravity on daily life as well as its effect on materials synthesis.

\section{Education Networking}

The Continuing Education Committee also coordinated a networking session on ways to encourage science understanding and pique scientific interest among students in grades $\mathrm{K}$ through 12 . Attendees discussed the merits of teaching the basic disciplines of biology, chemistry, and physics and then applying them, as is currently done, versus changing the curriculum to hook kids first with applications and the relationship of science to society, and later drawing the students in to gain a deeper understanding of the fundamentals.

Less costly and less political measures to integrate science into K-12 education were suggested. One involved linking scientists

Fifteen winners were chosen from among 28 graduate student award finalists at the 1990 MRS Fall Meeting. Standing (left to right): Quing Ma, Michael F. Roberts, Tak Keung Cheng, bel P. Nic, Timothy Foecke, J. Vrijmoeth, Joao L. Vargas, Thomas M. Breunig, Laurence D. Howe; seated (left to right): Sossina M. Haile, Gilles Chanvillard, Chang-Beom Eom, Cho-Jen Tsai, Yinshi Liu, Cathy Lane.
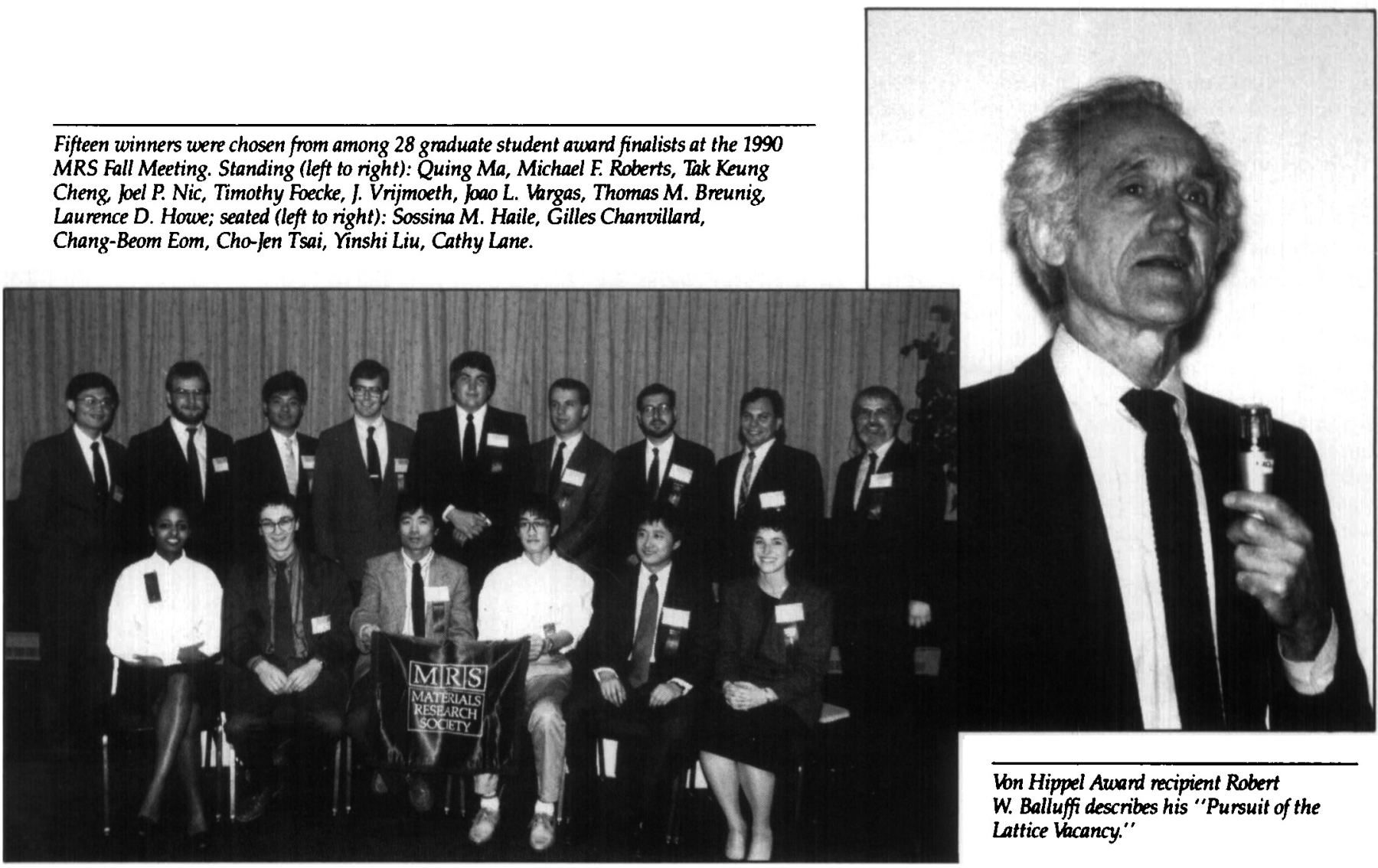
with students and teachers through scientific meetings, science fairs, and other programs on the turf of both teachers and scientists. Another suggestion was the use of in-service training so teachers could become more comfortable with science themselves, and in turn integrate science into the curriculum in a natural way. Yet another suggestion was to improve general scientific literacy through the media and personal communication. This also depends on scientists learning how to explain their work on the level of any eager listener.

The networking session was only modestly attended since it was in competition with the very popular poster sessions and also opposite the late-news session on Buckminsterfullerenes. Popularly called "Buckyballs," the newly produced form of carbon consists of a cluster of 60 atoms shaped something like a soccer ball. The molecules can be produced in large amounts ( 10 grams a day) by attaching two graphite rods to an ordinary arc welder, running a current through the rods, and vaporizing the carbon. This form of carbon may be useful as a lubricant since the structure, though stable, is weak and moves about easily.

With so much going on, each participant can absorb only a small fraction of the meeting. Below, the symposium organizers describe some of the high points from their sessions to keep you up to date in areas other than your own. Even here, we can only give a small snapshot of activity. For more, talk to your colleagues and read the proceedings.

\section{Surface Chemistry and Beam-Solid Interactions (Symposium A)} MRS Symposium Proceedings, Vol. 201

Organizers: Harry Atwater (Califormia Institute of Technology), Frances A. Houle (IBM Almaden Research Center), Doug Lowndes (Oak Ridge National Laboratory).

Support: IBM-Almaden Research Center; Martin Marietta Energy Systems; Coherent Laser Products Group; Lambda Physik, Incorporated; National Electrostatics Corporation; Anatech, Ltd.; Ion Tech, Inc.; Commonwealth Scientific Corporation.

This four-day symposium emphasized the interactions of low-energy ionized and neutral particle beams and photon beams with surfaces, films, and adsorbed layers. Approximately 135 papers were presented, and a 45-paper poster session covered the full range of beam-solid interactions.

During the session on high-resolution imaging of ion damage and on ion implantation, M. Bode (AT\&T Bell Laboratories) described TEM studies of the damage from passing single ions through an AlGaAs/ GaAs superlattice and control of defect motion by applying electric fields. Implantation to create optical materials was discussed by A. Polman (AT\&T Bell Laboratories), who presented results of $\mathrm{Er}$ doping of $\mathrm{SiO}_{2}$ for formation of a material having strong photoluminescence at 1.55 $\mu \mathrm{m}$. Similar studies of Si doping were described in a late-news paper.

Another series of papers addressed beam-induced phase transformations. The production of defects during high-energy implantation has been used to achieve control over Si microstructure. A. Priolo (Univ. of Catania) described the competition between damage accumulation and defectdriven annealing in crystalline $\mathrm{Si}$ depending on implantation conditions. Related work reported by J.S. Im (Caltech) investigated nucleation phenomena in amorphous Si. C. Volkert (AT\&T Bell Laboratories) demonstrated the relationship between defects and strain in implanted $\mathrm{Si}$. Irradiation-induced amorphization of intermetallic compounds was discussed by P. Okamoto (Argonne National Laboratories) in the context of thermodynamic melting and mechanical deformation. The role of volume change and elastic softening of the crystal were emphasized.

The session on low-energy beam processing covered the interplay between deposition and etching using hot neutrals and cold ions. R. Madix (Stanford Univ.) described experiments in which supersonic molecular beams were used to facilitate molecular dissociation, resulting in kinetic energy thresholds for reactions at surfaces. The complex interplay of dynamic variables involved in these dissociative reactions was discussed. D. Eres (Oak Ridge National Laboratory) continued this theme, describing several advantages of supersonic molecular jets for epitaxial growth of Ge films in GaAs (100), including high growth rates and control of film morphology and electrical properties.

S. Barnett (Northwestern Univ.) led off a session on ion-assisted epitaxy by describing work in which ion bombardment was shown to modify the growth mode from layer-plus-island to layer-by-layer for thin InAs films on $\mathrm{Si}$. In a session on lowenergy mixing and sputtering, Y.T. Cheng (GM) compared high-and low-energy ion mixing mechanisms as a function of temperature.

In-situ diagnostic techniques were the subject of the session on diagnostics and microcharacterization. Several papers discussed applications of Raman spectroscopy, including a talk by I. Herman
(Columbia Univ.) on Raman probes of laser deposition of $\mathrm{Si}$, and laser etching and oxidation of copper to obtain chemical and structural information in real time.

Aspects of laser chemical processing were treated next in two sessions on laser etching and film deposition. Progress in gaining a detailed understanding of chemical reaction mechanisms and materials issues was evident in the papers presented. The etching talks primarily covered pulsed laser etching of compound semiconductors and polymers. E. Kay (IBM) presented a study of debris-free laser ablation of plasma-polymerized fluorocarbon films of low dielectric constant. Laser photochemical and thermal deposition of a variety of materials was described, with an emphasis on materials synthesis and control of contamination. K. Singmaster (San Jose State Univ.) demonstrated deposition of pure $W$ and Mo films from the hexacarbonyls under conditions where dissociative adsorption of $\mathrm{CO}$ was uncompetitive with simple desorption.

In the laser ablation session, D. Geohegan (Oak Ridge National Laboratory) described in-situ emission, absorption and ion probe techniques for measuring kinetic energies and number densities of ionized and neutral ablated species. The effects of ambient gas on these distributions was also determined. Related talks on ablative plasma dynamics from threshold up to the higher fluences used for film growth were presented for a wide variety of materials. $P$. Brewer (Hughes) described experiments in which a low fluence excimer laser beam was used to reversibly control the composition, structure and chemical properties of a $\mathrm{CdTe}(100)$ surface by a process involving bond dissociation and thermal desorption of photo-generated surface fragments, not by surface melting.

The level of chemical and physical detail now available was unimagined 10 years ago, and we look forward to a continued deepening of our understanding and to increasingly sophisticated applications resting on that insight.

\section{Electronic, Optical and Device Properties of Layered Structures (Symposium B) \\ MRS Extended Abstract, Vol. EA-21}

Organizers: John Hayes (Bellcore), Mark S. Hybertsen (ATET Bell Labomtories), Eicke R. Weber (University of Califormia, Berkeley).

Support: Epitronics, Inc;; Office of Naval Research; Epitaxial Products International; BioRad Laboratories; EPI Chorus Corporation; Bellcore; ATET Bell Laboratories.

The objective of this symposium was to 
bring together scientists interested in the basic physics of novel thin film structures, the materials problems of such structures, and their device applications. Fourteen invited papers, 50 oral presentations, and 23 posters were included in the four-day program. The highlight of the symposium was a joint plenary session with the symposium on Long Wavelength Semiconductor Devices, Materials and Properties ( $\mathrm{T}$ ) and the symposium on Nanostructures: Fabrication and Physics ( $Y$ ). The joint session featured invited talks by A.C. Gossard (Univ. of California, Santa Barbara), N.K. Dutta (AT\&T Bell Laboratories), R. Landauer (IBM), and E.D. Wolf (Cornell), who gave an excellent introduction to the novel physics, device possibilities and processing problems of nanostructures.

The papers presented in this symposium stretched over a wide range of thin film structures, encompassing IV/IV, III/V, and II/VI heterostructures of the semiconductor/semiconductor and semiconductor/metal type, and discussing the issues of the fundamental physics, device applications, and materials problems of these structures.

Posters were integrated into the sessions by presenting them in the back of the meeting room during and after the sessions. Extended abstracts from the symposium were also available at the meeting.

\section{Evolution of Thin Film and Surface Microstructure (Symposium C)}

MRS Symposium Proceedings, Vol. 202

Organizers: Carl V. Thompson (Massachusetts Institute of Technology), Jeffrey Y. Tsao (Sandia National Laboratories), David J. Srolovitz (University of Michigan).

Support: EPI Systems Division-Chorus Corporation; Anatech Ltd.; FEI Company; Instruments SA Inc., Riber Division; Exxon Research and Engineering Corporation.

This symposium brought together people interested in both theory and experiments, as well as applications of thin films. Invited talks spanned a wide range of topics including nucleation, growth and coarsening during film formation, as well as modeling and experimental investigations of the evolution of the surfaces of films and substrates during film growth. Other topics included the formation of defects in heteroepitaxial films, the effects of ion bombardment on the evolution of microstructures, and modeling of grain growth in polycrystalline films.

John Cahn's (NIST) talk on nucleation drew an especially large crowd. He discussed the importance of the energies of the free surfaces of nuclei (in addition to the nucleus/substrate interfaces) in con- trolling film/substrate orientation relationships. Another very successful session, carried out jointly with Symposium J, highlighted recent advances in the use of diffraction techniques for in-situ characterization of surface and film evolution. Another topic which drew many attendees and contributed papers was misfit accommodation in heteroepitaxial films.

While many of the contributed papers dealt with materials systems of interest for specific applications, such as silicides and heteroepitaxial semiconductors, most of the papers and the discussions as a whole also focused on developing a deeper general understanding of the materials science of thin films. In this, the organizers felt the symposium was very successful.

\section{Electronic Packaging Materials Science (Symposium D)}

MRS Symposium Proceedings, Vol. 203

Organizers: Edwin D. Lillie (Microelectronics $\mathcal{E}$ Computer Technology Corporation), Ralph J. Jaccodine (Lehigh University), Paul Ho (IBM T.J. Watson Research Center), Kenneth Jackson (University of Arizona).

Support: Office of Naval Research; AlliedSignal, Inc.; Amoco Chemicals Company; Dow-Coming Company; INTEL Corporation.

This symposium, the fifth in a series devoted to the technology of microelectronics packaging and interconnect from a materials perspective, featured 80 papers, 23 of which were from invited speakers.

There were sessions on the mechanical and deformation properties of polymer interfaces (with emphasis on the effects of plastic behavior in polymeric thin films, and general attention to stress effects on reliability), protective coatings for ICs, polymers and polymer-processing for high density packaging (e.g., photoimageable polyimides, use of liquid crystals to control thermal expansion, effect of curing on stress in polyimides in multilayer structures), ceramics and glass-ceramics (emphasis on aluminum nitride bulk, and interface properties), metallization techniques (low temperature CVD of copper films, laser planarization, laser assisted deposition of catalysts for electroless and electrolytic plating of copper), solders and soldering (including fatigue life predictions for solder joints), and measurement of material properties of thin films.

Overview talks included one by Rao Tummala (IBM) on ceramic and glassceramic packaging. Gene Rymaszewski (Renesselaer Polytechnic Institute) reviewed the role of thin films for multi-chip modules. Joseph Carpenter described NIST's initiative in developing measurement techniques for electrical, thermal and mechanical properties of features in the size-range relevant to the field. Barry Johnson reviewed materials for high performance packaging, and Jim Economy talked about possibilities for designing polymers as dielectrics with exceptional electrical and mechanical properties. Ron Latanision described the technical work that led to MIT's new Packaging Consortium, which aims to provide in-depth understanding of metal-polymer interfaces and processes at interfaces in high-density substrates.

The symposium was standing-room only much of the time, and the audience was enthusiastically involved.

\section{Chemical Perspectives of Microelectronic Materials II (Symposium E)}

MRS Symposium Proceedings, Vol. 204

Organizers: Lawrence H. Dubois (ATET Bell Laboratories), Mihal E. Gross (AT\&T Bell Laboratories), Leonard V. Interrante (Rennselaer Polytechnic Institute), Klavs F. Jensen (Massachusetts Institute of Technology).

Support: AKZO Chemical, Inc.; American Cyanamid Company; Matheson Gas Products; Office of Naval Research; Strem Chemical, Inc.

This was the second symposium devoted to the role of chemistry in preparing and manipulating materials used in microelectronic applications. Nine invited talks, 67 oral presentations, and 47 posters spanned fundamental surface chemistry in chemical vapor deposition (CVD) and etching; synthesis of novel precursors for CVD of metals, semiconductors, and dielectrics; in-situ monitoring techniques; modeling of chemical reaction mechanisms and reactor configurations; and materials characterization.

Based on the work presented at this symposium, the understanding of fundamental surface and gas-phase chemistry underlying CVD processes has increased substantially since the last symposium. This trend will continue as the number of researchers in the field expands. Basic surface reaction mechanisms involved in film growth of metals (e.g., $\mathrm{W}$ and $\mathrm{Al}$ ) and semiconductors (e.g., Si and GaAs) were explained in detail. The application of UHV surface science techniques, along with gas-phase spectroscopies have been instrumental in unraveling the complex interaction of gas-phase and surface reactions characteristic of actual CVD and etching systems. The papers demonstrated a continuing development of in-situ gas-phase and surface spectroscopies for detecting intermediates in CVD processes, in particular for metalorganic deposition of compound semiconductors. This development will further enhance the understand- 
ing of chemical mechanisms behind CVD and etching.

Metalorganic precursors featured prominently in many of the presentations. Related to Si technology, new solid and liquid precursors were reported for CVD of $\mathrm{Cu}$ and $\mathrm{Al}$, which are of interest to the next generation of ULSI circuits. MOCVD of $\mathrm{Au}$ was also discussed, along with an electrochemical scheme for repairing defects in large area $\mathrm{Cu}$ circuits. Novel precursors for silicon nitride and silicon oxide relevant to Si technology were also presented. In the compound semiconductor area, growth of high purity $\mathrm{GaAs} / \mathrm{AlGaAs}$ structures and selective deposition of $\mathrm{GaAs}$ using new $\mathrm{Al}$ and $\mathrm{Ga}$ sources was the topic of several papers. Related compounds were used to deposit $\mathrm{AlN}$ and GaN. Investigations of novel precursors for MOCVD of CdTe and $\mathrm{ZnSe}$ were also reported. Major advances have been achieved in the synthesis of single-source precursors for the growth of compound semiconductors. Considerable effort is still required, however, to improve source volatility and the understanding of decomposition chemistry.

The meeting's large, lively audience reflects an increased awareness of the relevance of and the potential for chemical research in materials used in microelectronic applications.

\section{Kinetics of Phase Transformations (Symposium F)}

MRS Symposium Proceedings, Vol. 205

Organizers: Michael O. Thompson (Comell University), Michael J. Aziz (Harvard University), G. Brian Stephenson (IBM T.J. Watson Research Center).

\section{Support: Computer Graphic Service.}

This symposium touched on a wide range of topics covering the kinetics of phase transformation, including ionbeam-induced amorphization and crystallization processes, order-disorder transformations, solid-state amorphization, defects and kinetics of amorphous $\mathrm{Si}$, and solidification. Invited speakers, including David Turnbull on solidification and Lindsay Greer (who received the Zachariasen Award at the meeting) on solid-state amorphization, provided insightful overviews to current research problems. Results from two of the topics, amorphous $\mathrm{Si}$ and the fundamental aspects of ordering, were particularly timely and are discussed further below.

Many new and important results on amorphous $\mathrm{Si}$ were presented in a series of sessions, with amorphous $\mathrm{Si}$ continuing, despite over 20 years of study, to exhibit surprisingly complex behavior. The most dramatic change during the past year has been the growing acceptance of "active" point defects in amorphous $\mathrm{Si}$, and the realization that these defects play a major role in the structural relaxation, and in determining solubilities and diffusivities of impurities. L. de Wit presented data showing that amorphous $\mathrm{Si}$ continues to undergo structural relaxation even at annealing temperatures of $850^{\circ} \mathrm{C}$. Additional effects of the relaxation were reported by groups studying the density and viscosity of amorphous Si during annealing, with some results suggesting that the relaxation is directly related to dangling bond annihilation. One of the most dramatic manifestations of structural relaxation was reported by Coffa where the solubility of fast diffusers in amorphous $\mathrm{Si}$ was shown to decrease with degree of relaxation. Effects of impurities and hydrostatic pressure on solid phase epitaxial growth were also discussed with an emphasis on the implications these effects have on various defect models. In what was probably the most unexpected result, J.A. Roth and G.L. Olson showed that hydrogen, ubiquitous as it is, dramatically reduced the epitaxial growth rate. Although the mechanisms of relaxation and solidphase epitaxy remain open questions, it is clear that the data presented at this symposium have substantially advanced our understanding, as well as altered our view, of amorphous $\mathrm{Si}$.

Two sessions focused on fundamental aspects of clustering, ordering, and nonlinear diffusion. Peter Voorhees presented calculations of complex equilibrium shapes for misfitting particles in an elastically anisotropic medium, and showed how the evolution of shape with size destroys scaling during coarsening. Karl Ludwig discussed the relationship between the early stage of ordering and the equilibration kinetics of short-range order, finding that the extent of the early stage before the onset of coarsening depends strongly on initial conditions. Experimental, theoretical, and numerical simulation studies were contributed on a wide variety of topics: coarsening during phase separation, segregation, ordering, and coherency strain at interfaces, the coupling of ordering and phase separation, and nonlinear effects during ordering and short-range interdiffusion. One theme which emerged is the importance of Monte Carlo simulations as a necessary tool for understanding the atomic structure and nonlinear kinetics of systems with short-range interactions.

\section{Clusters and Cluster-Assembled Materials (Symposium G)}

MRS Symposium Proceedings, Vol. 206

Organizers: Robert S. Averback (University of Illinois), David L. Nelson (National Science Foundation), J. Bermholc (North Carolina State University).

Support: Office of Naval Research.

This symposium focused on the production, characterization, and materials aspects of clusters and cluster-assembled materials. New methods of cluster synthesis now make it possible to produce clusters of almost any material, and new developments presented during the symposium have considerably enhanced the efficiency of cluster sources. These sources can deposit thin films of monodispersed clusters at practical growth rates. The first cluster sources that can produce beams of mass-selected neutral clusters have also been built. These sources, which rely on charge-transfer reactions after mass selection, offer considerable advantages for studies of cluster properties and reactivity in a well-characterized environment.

Cluster interactions with surfaces was another topic covered in depth. Scanning tunneling microscopy investigations have shown that clusters coalesce on surfaces, yet specific conditions lead to a welldefined distribution of cluster sizes at the surface. This distribution can be narrowed further by selective excitation of specific cluster sizes. The collisions of clusters with the surface are beginning to be studied in detail, and both "soft landing" and collision-induced fragmentation have been observed experimentally as well as modeled theoretically.

Clusters melt at temperatures far lower than bulk. This is also true of clusters on surfaces and the decrease in the melting temperature with cluster size appears to saturate at nanometer cluster sizes. It is now well established that cluster deposition can lead to metal-semiconductor interfaces far superior to those obtained by conventional deposition techniques. The microscopic mechanisms of this process are yet to be uncovered, even the cluster size distribution is controversial, and a substantial amount of experimentation as well as new theoretical development are required.

For isolated clusters, the theory has now progressed to where clusters up to $50-60$ atoms can be studied by first-principles techniques, which also include dynamical methods to investigate time-dependent and/or finite temperature properties. Larger systems have been explored by using force fields and classical potentials fitted to both the experimental data and the results of quantum-mechanical calculations. Significant progress in this area has 


\section{Late-News Session Highlights Buckminsterfullerenes}

The special late-news session held November 29, 1990, gave MRS Fall Meeting attendees an opportunity to present and discuss the results of intense research that followed the surprising September 1990 announcement of the synthesis and isolation of $100-\mathrm{mg}$ quantities of molecular carbon clusters (Nature 347, 1990, p. 354).

The announcement reported that soot produced by vaporizing graphite contains a large fraction of $\mathrm{C}_{60}$, a 60 -atom, allcarbon molecule, and also a smaller abundance of other species such as $C_{70}$ and $C_{84}$. These molecular species are apparently hollow, spheroidal structures of pure carbon, previously postulated on the basis of molecular beam mass spectrometry experiments and theoretical calculations.

Carbon-60 in particular has received considerable attention as a new form of molecular carbon whose structure exhibits a soccer ball or geodesic sphere-like pattern consisting of 60 carbon atoms. Hence the name "Buckyball" as a tribute to Buckminster Fuller, the inventor of the geodesic dome.

Twenty-four papers were presented at the MRS late-news session called "Buckyballs: New Materials Made from Carbon Soot." Attended by over 350 people, the marathon session began at 5:15 p.m. and continued until 12:45 a.m. the following morning (with over 70 participants still contributing to the discussions).

In the three months since the announcement of this breakthrough, many research groups worldwide have been exploring the fundamental properties of these novel materials, both as molecular entities and as building blocks for new classes of materials. The research results reported at the MRS Fall Meeting fell into two categories: molecular and material characterization, and chemical properties. In addition, an instrument that uses an arc discharge and helium flow system to scale up the production of molecular carbon clusters to 10 grams per day was described.

Results of molecular characterization highlighted both structure and dynamics. Carbon-13 NMR experiments showed that both $C_{60}$ and $C_{70}$ have spheroidal structures. Carbon-carbon bond distances in $\mathrm{C}_{60}$ obtained from EXAFS and solid-state NMR were found to be consistent with those theoretically predicted for the hollow spheroidal structure. Observations of $C_{60}$ molecules by scanning tunneling microscopy and transmission electron microscopy were reported. The infrared, ultraviolet-visible and Raman spectra for both $\mathrm{C}_{60}$ and $\mathrm{C}_{70}$ films have been obtained. Several groups reported on $x$-ray crystallographic studies where lattice parameters have been determined, but to date the precise atomic positions of the carbon atoms in the $\mathrm{C}_{60}$ molecular solid are still undetermined.

Solid-state, low-temperature NMR studies showed that even at $123 \mathrm{~K}$ individual $\mathrm{C}_{60}$ molecules are still rotating or librating relative to each other. Thermal desorption mass spectrometry showed evidence that other molecular carbon species such as $\mathrm{C}_{80}$ and $\mathrm{C}_{84}$ are also produced, although in much lower abundance.

The chemistry of fullerenes is beginning to emerge, and may be the beginning of a very active field in molecular and solidstate chemistry. It was reported that after they are extracted from the soot with toluene or benzene, the fullerenes can be isolated relatively easily either by chromatography or sublimation. Three different kinds of chemical transformations were described together with fundamental photochemical and electrochemical processes.

Fullerenes can be chemically modified by the Birch reduction process to produce $\mathrm{C}_{60} \mathrm{H}_{18}$ and $\mathrm{C}_{60} \mathrm{H}_{36}$, and the process was shown to be completely reversible. This observation may indicate feasibility for reactions leading to linkage between two cages, and the subsequent formation of polymers derived from fullerenes as monomers.

Electrochemical studies on $\mathrm{C}_{60}$ and $\mathrm{C}_{70}$ to form the singly, doubly and triply reduced anions open the way to electrochemical generation of interesting compounds. A tetraphenyl phosphonium salt, prepared electrolytically at a platinum cathode, was described as a semiconducting, microcrystalline black powder, insoluble in all common organic solvents.
Two $\mathrm{C}_{60}$ derivatives were reported. One, a diosmylate ester, can apparently can be used to oxidatively open the fullerene sphere, although the data presented were too preliminary to conclude that a hole had been punched into the sphere. However, this could be thought of as a first step toward reversibly opening the cage in order to seal metal atoms inside, thereby providing a way to modify the properties of molecular carbon materials.

Intriguing photochemical and electrochemical properties suggest that $\mathrm{C}_{60}$ could have adverse environmental effects. This molecule was reported to be a strong oxidant (Eo $=-0.2$ volts versus $\mathrm{Ag} / \mathrm{AgCl}$ in tetrahydrofuran) and a powerful photosensitizer and efficient catalyst for converting normal (triplet) oxygen to its reactive singlet form. These facts have important physiological consequences, and researchers have been warned to take precautions against skin contact and breathing the dusts until the physiological properties of the material have been better characterized.

Most researchers are focusing on developing a better understanding of the physical and chemical properties of the fullerenes, with the expectation that their unique chemical, optical, electronic, and tribological properties will lead to novel applications.

Although the discussion of scientific results was good, there was some reluctance to speculate in any detail on the technological opportunities that could arise from chemically modified $C_{60}$ and other forms of hollow molecular carbon.

Andrew Kaldor, Exxon

Donald M. Cox, Exxon

Robert S. Averback, Unioersity of Illinois J. Bermholc, North Carolina State University David L. Nelson, NSF 
been achieved in the last few years.

Nanometer-size semiconductor clusters also show quantum confinement and may have applications in nonlinear optics. The keynote speaker addressed some of the challenges faced by synthesis chemists to produce device materials from these clusters. Methods are needed to synthesize perfectly periodic arrays of mono-sized clusters that are readily packaged as thin films or bulk material. Various avenues for self organization, such as using threedimensional host surfaces, are being explored. The chemistry of Buckminsterfullerene was used to illustrate a direct link between gas-phase cluster chemistry and materials synthetic chemistry. The functionalization of "Buckyballs" creates the possibility for using them in extended crystalline solid networks (Buckyball-zeolites), polymerization, and mixed-valence electronic arrays.

Finally, the latest developments in nanophase materials were reported. A wide range of these materials has now been synthesized, including several pure metals, intermetallic compounds, metallic glasses, ceramics, and composites. Although inert gas condensation methods are primarily used for producing these materials, other more efficient methods were discussed, particularly for ceramics. Several properties of nanophase materials that derive directly from their unique microstructure were addressed; these included new alloy phases, high hardness in metals, and superplasticity in ceramics.

\section{Materials Issues in Applications of Ceramic Superconductors (Symposium H)}

Organizers: Allen M. Goldman (University of Minnesota), Kenneth W. Lay (GE Corporate Research and Development Center), Julia $M$. Phillips (ATET Bell Laboratories), Anthony C. Schaffhauser (Oak Ridge National Laboratory).

Support: Argonne National Laboratory.

This five-day symposium was the sequel to the successful forums on the subject provided at previous MRS meetings, beginning with the first public discussions of high-temperature superconductivity (HTS) at the 1986 MRS Fall Meeting. Like its predecessors, the symposium was a major venue for exchanging important new results and discoveries in the field. Over 350 papers were presented in oral and poster presentations. In addition, an animated panel discussion, attended by some 150 scientists and engineers, dealt with the prospects for applying bulk and thin film ceramic superconductors.

In the general area of bulk materials,
$\mathrm{YBa}_{2} \mathrm{Cu}_{3} \mathrm{O}_{7-\delta}$ (YBCO) continues to be plagued by weak links that reduce the current carrying capability in polycrystalline samples. However, considerable progress is being made in relating structure to properties, for example, by studying special grain boundaries. Flux flow and creep in YBCO can be low if pinning sites are present. Various studies propose oxygen defects or cation substitutions as possible pinning centers.

The understanding of $\mathrm{Bi}-$ and $\mathrm{Tl}$ containing based superconductors (BSCCO and TBCCO, respectively) is less developed. The phase equilibria in these systems still need considerable work. Flux flow and creep remain high, especially at high temperatures. The irreversible temperature, however, has been shown not to be an intrinsic property of the material. Neutron irradiation and fission particle damage have shown reduced flux creep upon introduction of defects into BSCCO. Most exciting from a practical standpoint is the continuing progress toward developing long conductors, especially in BSCCO in silver. The overview talk by K. Sato of Sumitomo showed prototypes of leads, monofilament and multifilament tapes.

Progress continues on thin film materials. Films must now meet a series of benchmarks in order to be considered "high quality" by the community. The very different nature of ceramic superconductor materials compared with conventional superconductors has necessitated a slower progression along the "materials food chain" than might have been expected only a few years ago. The first rather trivial products utilizing high $\mathrm{T}_{\mathrm{c}}$ superconducting thin films, such as films, patterned films, and microwave components are now available. More sophisticated products and applications can be expected as materials mastery and market demand allow.

Individuals investigating the growth and properties of high $\mathrm{T}_{\mathrm{c}}$ thin films continue to achieve greater control over the materials, so that increasingly complex structures can be grown.

Multilayers involving YBCO and a nonsuperconductor such as $\mathrm{PrBa}_{2} \mathrm{Cu}_{3} \mathrm{O}_{7-6}$ (PBCO) have been available for some time, but issues have arisen regarding the abruptness of the interfaces between layers. A powerful, relatively new analytical technique, Z-contrast scanning transmission electron microscopy (STEM), has demonstrated that there is no observable interdiffusion between layers in a superlattice consisting of one unit cell of YBCO alternating with 8 unit cells of PBCO. Laser molecular beam epitaxy, discussed in an invited talk by T. Kawai (Univ. of Osaka) is a powerful technique for fabricating artificially layered structures, including a variant of BSCCO which has six $\mathrm{Cu}-\mathrm{O}$ planes. While it is not yet known whether or not this material is superconducting, this group has shown that its analog, which contains five $\mathrm{Cu}-\mathrm{O}$ planes, has a $\mathrm{T}_{\mathrm{c}}$ of $50 \mathrm{~K}$.

\section{Mechanical Properties of Porous and} Cellular Materials (Symposium I)

MRS Symposium Proceedings, Vol. 207

Organizers: Loma J. Gibson (Massachusetts Institute of Technology), David Green (Pennsylvania State University), Karl Sieradzki (The Johns Hopkins University).

Support: ICI Polyurethanes; Alcan International Ltd.; Mobay Corporation; Pennsylvania State University.

This symposium successfully brought scientists together from a wide variety of disciplines to focus on the mechanical behavior of porous and cellular solids composed of metals, ceramics, polymers, or biological materials.

For cellular materials, papers ranged from processing techniques through microstructure-mechanical property relationships to design. In an overview talk, Mike Ashby (Cambridge Univ.) showed how porous cellular materials can be more efficient than dense materials in designs that require minimum weight. He indicated that many biological materials have been able to accomplish such efficiency but there exists an opportunity to design even more efficient, manmade materials controlling microstructures at different scale levels.

In the area of processing, James Aubert (Sandia National Laboratories) discussed techniques for manipulating polymersolvent phase equilibria to control the microstructure of microcellular foams. Other papers on processing discussed the production of cellular ceramics by CVD, HIPing and sol-gel techniques.

Papers on the mechanical behavior of cellular materials considered various ceramics, microcellular polymers, conventional polymer foams and apples. There were also contributions that considered optimum design procedures for cellular materials. Steven Cowin (City Univ. of New York) discussed procedures to match the discrete microstructural aspects of cellular materials with the continuum mechanics approach to their elastic behavior.

Other papers considered the role of pores in the ductile failure of metals and the mechanical response of porous composites during HIPing. David Srolovitz (Univ. of Michigan) discussed techniques for simulating microstructural features, 
such as porosity, in the computer modelling of elastic-brittle spring networks. Another interesting group of papers considered the deformation processes in power beds and other particle networks.

The final session of the symposium was held in conjunction with Symposium W. Phil Duxbury (Michigan State) gave an overview of scaling theory with respect to the elastic and fracture behavior in disordered solids. Several other papers considered this topic in detail.

\section{Advances in Surface and Thin Film Diffraction (Symposium J) \\ MRS Symposium Proceedings, Vol. 208} Organizers: Philip I. Cohen (University of Minnesota), David J. Eaglesham (ATET Bell Laboratories), Ting C. Huang (IBM Almaden Research Center).

Support: JEOL USA, Inc.; Intermational Scientific Instruments (ISI), Inc.; Philips Research; Field Emission Incorporated; Instruments SA-Riber Div.; Staib Instruments; Blake Industries; Rigauku USA, Inc.; Thermionics.

This symposium succeeded in bringing together a wide range of studies using different diffraction techniques to study structures and processes at surfaces. Adsorption processes were widely studied: A. Ichimiya, for example, presented RHEED observations on the structure and bonding properties of adatoms on $\mathrm{Si}(111)$. J.M. Gibson showed beautifully detailed data on the initial stages of oxidation of this surface. Oxide formation on Si was also studied by T.A. Rabedeau, who used grazing incidence $x$-rays to eliminate models involving crystalline oxide at the $\mathrm{Si}-\mathrm{SiO}_{2}$ interfaces. E. Vlieg and R.J. Van Silfout showed that this technique is also beginning to shed light on the atomistic processes of growth. In the joint symposium on epitaxy P.A. Bennett and P.H. Fuoss gave elegant demonstration of different techniques for measuring step correlations.

Some novel techniques were described: In a late-news paper, Tong showed how to invert forward scattering diffraction data from point sources in a surface to obtain structural images; C.C. Ahn used spectacular reflection EELS data in a RHEED configuration to obtain accurate measurements of sub-monolayer coverage; W.N. Unertl showed how low resolution imaging and high transfer width LEED could be combined in the same apparatus; and W. Parrish described how to apply a rotating anode $x$-ray source with $x$-ray optics and two channel monochromators to study single and multilayer films in which the intensities varied over six orders of magnitude.
Defects in Materials (Symposium K)
MRS Symposium Proceedings, Vol. 209

Organizers: Paul D. Bristowe (Massachusetts Institute of Technology), J. Eimest Epperson (Argonne National Labomatory), J.E. Griffith (ATET Bell Laboratories), Z. Liliental-Weber (Lawrence Berkeley Laboratory).

Support: Air Force Office of Scientific Research; Argonne National Labomatory; Philips Electronic Instruments; Blake Industries, Inc.; Eastman Kodak Company.

More than 200 papers were presented at this symposium, making it the largest at the Fall Meeting. Defects in all types of materials were investigated by a wide range of experimental methods. Twelve invited papers from the United States, United Kingdom, Germany, and Japan, 80 oral presentations, and more than 100 poster presentations filled the four-day symposium.

Presentations of experimental results were well balanced with theoretical papers. A half-day session was committed solely to theory. J.D. Joannopoulos (MTT) gave a well received presentation showing the use of modern graphic techniques instead of lengthy equations to understand theoretical results.

The symposium started with an excellent talk (C.G. Windsor, United Kingdom) that classified all types of defects from subatomic to submicron dimensions, and reviewed methods of their detection. This was followed by an invited presentation (R.W. Siegel, Argonne National Laboratory) showing the importance of grain boundary structures, especially in nanophase materials.

The role of point and line defects in semiconductors, metals and intermetallic compounds was discussed during the next two days, followed by discussions of defects on surfaces and at interfaces. An excellent talk (T.N. Theis, IBM) on DX centers in GaAs showed the complexity of deep level defects in semiconductors. Despite enormous theoretical and experimental efforts in the last decade, even fundamental issues including the microscopic configuration and the charge state still remain controversial. Another talk (R.J. Hamers, IBM) combined scanning tunneling microscopy with tunneling spectroscopy to show that atomic size defects influence the dynamic electronic properties of silicon surfaces.

The last day of the symposium was devoted to oxide superconductors and the role of defects in this class of materials. The large poster session encompassing all of the topics of the symposium was very well attended and gave an opportunity to discuss in detail many fascinating problems of defects and their role in a variety of materials.

\section{Solid State Ionics (Symposium L)}

MRS Symposium Proceedings, Vol. 210

Organizers: Gholam-Abbas Nazri (GM Research Laboratories), Robert A. Huggins (Stanford University), Duward F. Shriver (Northwestem University), Minko Balkanski (Universit-Pierre et Marie Curie).

Support: Office of Naval Research, Department of Energy; Los Alamos National Labomtory; Innovative Technology; Vacuum/ Atmospheres Co.

This symposium dealt with fundamentals, materials, techniques, and applications of solid state ionics. The second MRS symposium on this topic continued to show great vitality and interest in this interdisciplinary field. The symposium was a truly international forum on fast ion transport in solids, the physics and chemistry of insertion compounds, ionic and electronic conductive polymers, the application of novel in-situ and ex-situ techniques for materials characterization and application of solid state ionics materials in energy conversion devices, sensors, and electrochromic materials. Of the symposium's 137 presentations, 51 were from outside the United States.

Recent advances in application areas, including solid state lithium batteries, sodium-sulfur batteries, solid state fuel cells, sensors, and electrochromic windows were reported. State-of-the-art fabrication of thin film microbatteries and sensors were presented.

The symposium included presentations on ionically conductive polymers and their applications as solid electrolytes in batteries. Several new developments and key issues on polymer electrolytes were reported. Structure-conductivity relationship and ion-pairing in polymer electrolytes were examined.

New advances in the theory of charge and mass transport in crystalline solids, glasses, and polymeric materials were discussed.

In the area of low-dimensional materials, the principal features of insertion phenomena and physics and chemistry of intercalation compounds were presented. The structure-property relationships of mixed conducting materials were discussed from the view point of materials science, chemistry, and physics.

In the context of materials characterization, the use of both in-situ and ex-situ techniques (such as $x$-ray and neutron diffraction, EXAFS, IR and Raman spectroscopy, solid state NMR and ESR, XPS, 
TEM, impedance spectroscopy and electrochemical techniques) for the investigation of both structural and dynamic aspects of materials were presented.

The attendance and active interest in this symposium showed the dynamic character of the general interest in solid state ionics and the transition of this field from one of pure science into one with great technological opportunities.

\section{Dynamics in Small Confining Systems (Symposium M)} MRS Extended Abstract, Vol. EA-22

Organizers: J.M. Drake (Exxon Research and Engineering Company), J. Klafter (Tel Aviv University), R. Kopelman (University of Michigan).

Support: Office of Naval Research; Exxon Research and Engineering Company; NEC Research Institute.

Held for the first time as part of an MRS Fall Meeting, this symposium was quite broad in scope, covering both the dynamic and thermodynamic properties of confined molecular systems. Physicists, chemists, chemical engineers, and materials scientists gathered to share different points of view on complex molecular processes in a range of technologically important materials, including porous glasses, zeolites, polymers, micelles, and microemulsions. A total of 86 presentations included invited and contributed papers plus poster papers. The symposium was well attended and the discussions lively.

The symposium dealt with experimental and theoretical ways to describe the role of chemical and geometrical factors in confined systems. In general, researchers reported that confined molecular systems exhibit physical properties that are frequently different than those observed for the same molecules in the bulk. The approaches taken to understanding confined molecular systems have clearly benefited from the use of supercomputers for molecular dynamic calculations. However, there are still considerable differences between calculated and measured features suggesting the opportunity for future corroborative work.

There appears to be a continuing interest in the dynamics and thermodynamics of confined molecular systems. The symposium was an effective way to let investigators with different backgrounds know how common problems are being explored. We hope to organize a second symposium for the fall of 1992.

\section{Covalent Ceramics (Symposium N) MRS Extended Abstract, Vol. EA-23}

Organizers: Gary S. Fischman (New York State College of Ceramics, Alfred University), Terry Aselage (Sandia National Laboratories), Richard M. Spriggs (New York State College of Ceramics, Alfred University).

Support: Centorr Associates, Inc.; New York State College of Ceramics.

The symposium on Covalent Ceramics was held for the first time at an MRS Fall Meeting, but the turnout was higher than expected for a new program. The program began with a keynote paper by $W$. Williams (Case Western Reserve Univ.) entitled "Covalent/Metallic/Ionic Ceramics," with more than 100 people attending.

The program was divided into three major topics: modeling and basic theory, material preparation, and structure property relations. Chaired by T. Aselage (Sandia National Laboratories), A. Kingon (North Carolina State Univ.), G. Fischman (Alfred Univ.), C. Hubbard (Oak Ridge National Laboratories), and R. Spriggs (Alfred Univ.), respectively, these sessions were generally attended by 20 to 50 people.

\section{Fiber-Reinforced Cementitous Materials (Symposium O)}

MRS Symposium Proceedings, Vol. 211

Organizers: Sidney Mindess (University of British Columbia), Jan P. Skalny (W.R. Grace and Company).

Support: W.R. Grace E Co.-Conn.; VulkanHarex; Federal Highway Administration.

This symposium dealt with the relationships between the properties of the individual components of fiber-reinforced cements and concretes, processing techniques, and the properties of the resultant composites. Forty papers were presented (more than half by researchers from Canada, Europe, and Asia). The five session themes were toughening mechanisms, synthetic and glass fibers, impact loading, new fibers and processing techniques, and novel applications. The lively exchange of ideas should help in the further development of high-performance, durable fiber concretes.

\section{Scientific Basis for Nuclear Waste Management XIV (Symposium P) MRS Symposium Proceedings, Vol. 212}

Organizers: T. Abrajano Jr. (Argonne $\mathrm{Na}$ tional Laboratory), Lawrence H. Johnson (Whiteshell Nuclear Research Establishment).

Support: Argonne National Laboratory; U.S. Nuclear Regulatory Commission; Atomic Energy of Canada, Ltd.

In recent years, we have witnessed significant developments in our quest to understand how nuclear waste repository systems are likely to behave over long periods of time. The Fourteenth International Symposium on the Scientific Basis for Nuclear Waste Management was a solid testimony to this evolving state of understanding. Eight oral sessions and one poster session covered key areas of research, including characterization and degradation mechanisms of glass, ceramic, spent fuel and cementitious wasteforms, corrosion mechanisms of container materials, radionuclide release, speciation and transport in experimental and natural systems, and integrated assessment of repository behavior. Oral sessions were opened by invited speakers with international reputations. F. Parker delivered the keynote address entitled "Rethinking High-Level Radioactive Waste Disposal," which provoked discussions on the technical and ethical merits of current U.S. high-level waste disposal strategies. In spite of a myriad of concerns over approaches and policies, it was abundantly clear that solid scientific work, such as that presented in the symposium, will remain the cornerstone for promulgating a viable nuclear waste disposal option.

\section{High Temperature Ordered} Intermetallic Alloys (Symposium Q) MRS Symposium Proceedings, Vol. 213 Organizers: Lyman Johnson (General Electric Company), David P. Pope (University of Pennsylvania), James $\mathrm{O}$. Stiegler (Oak Ridge $\mathrm{Na}$ tional Laboratory).

Support: Air Force Office of Scientific Research; General Electric Aircraft Engines; Martin Marietta Energy Systems, Inc.

This symposium was the fourth biannual MRS symposium on this subject. A total of 198 papers were presented in the oral and poster sessions to consistently large audiences.

Many theorists are interested in understanding why intermetallics are often brittle. Some are brittle because they lack enough slip systems. Many theorists are attempting to find ways to decrease specific fault energies and thereby encourage the formation of specific dislocations, e.g., $1 / 2$ (111) dislocation pairs separated by $\mathrm{APB}$ in NiAl. To date these theoretical attempts have been unsuccessful, although there is hope for future success.

The properties of TiAl-based alloys received a great deal of attention, from both scientific and engineering points of view. The role of interstitials in controlling microstructure and mechanical properties is becoming recognized as very important, just as in disordered Ti-based and $\mathrm{Ti}_{3} \mathrm{Al}$-based alloys. It was very exciting to learn that a 
number of $\mathrm{TiAl}$ - and $\mathrm{Ti}_{3} \mathrm{Al}$-based alloys are now being tested in aircraft engines.

Unlike previous symposia that focused on intermetallics with the $\mathrm{L}_{2}$ and $\mathrm{B} 2$ crystal structures, this time many presentations reported on more exotic structures- $-\mathrm{DO}_{22}, \mathrm{C} 15, \mathrm{~A} 15$, and $\mathrm{C} 11_{\mathrm{b}}$, for example. Furthermore, great strides have been made in processing techniques for intermetallics, in crystal growth, powder processing, spray forming, and in the production of intermetallic matrix composites. Finally, there is increased interest in the environmental resistance of certain intermetallic-based alloys, perhaps indicative of intermetallics being considered for more end uses.

\section{Optical and Electrical Properties of Polymers (Symposium R1)} MRS Symposium Proceedings, Vol. 214 Organizers: John A. Emerson (Sandia National Laboratories), John M. Torkelson (Northwestern University).

This symposium extensively discussed the current state of second-order and thirdorder nonlinear optical effects in polymers, which included discussions of new materials and their measured susceptibilities. Ways to make conductive polymers were described as well as the properties and conduction mechanisms of both doped and undoped conductive polymers. Theoretical interpretations of electrical properties were also discussed. New measurement techniques, for example, with microwaves or electrochemically, were also presented.

\section{Synthesis and Properties of New Catalysts: Utilization of Novel} Materials Components and Synthetic Techniques (Symposium S)

\section{MRS Extended Abstract, Vol. EA-24}

Organizers: Edward W. Corcoran Jr. (Exxon Corporate Research Science Labs), Marc J. Ledoux (Universite Louis Pasteur Strasbourg), Jack R. Knox (Knox Consulting Company).

Support: Air Products and Chemicals, Inc.; American Chemical Society Petroleum Research Fund; Amoco Oil and Chemical Companies; Exxon Chemicals, Inc.; Exxon Chemical Co.; Exxon Corp.; W.R. Grace and CompanyResearch and Davison Chemical Divisions; Mobil Research and Development Corporation; National Aeronautics and Space Administration; Pechiney Corporation; UOP Corporation.

The interest in this symposium was quite high as is clear from the extensive financial support. More than 70 papers were presented, focusing on developments in synthesis and identification of new classes and types of catalytic materials. The contributions were organized into eight sessions covering microporous materials, layered materials, oxides, carbides, sulfides, nitrides, and metals in catalysis.

The symposium opened with a session on oxide materials with several papers on the use of oxides to activate methane. There were also contributions on metals and supported metals in catalysis, with notable discussions on metal clusters, colloidal metals, amorphous metals, and synthetic routes to these materials. Other papers focused on the characterization of these catalysts and evaluation of their catalytic properties.

A significant part of the symposium was devoted to the discussion of microporous catalysts. Some papers centered on phosphate-based molecular sieves including developments with the very large pore material, VPI-5. Discussions also addressed new methods for preparing molecular sieves, their characterization, and catalytic evaluation. A wide variety of contributions described new types of clays and other layered materials, with several papers reporting on new pillaring agents and catalytic applications.

Another section of the symposium was devoted to carbide, nitride, and sulfide materials. Carbides and nitrides have been identified as potential substitutes for metal catalysts and supports in a variety of industrial applications. New approaches addressed synthesis and activation problems that normally prevent their large-scale application. These elegant solutions should now generate renewed interest in this area. Other notable contributions examined preparation techniques for sulfides and the function of structure on catalyst activity for these materials.

Several papers discussed novel synthetic techniques applicable to a wide range of catalyst types. Additionally, many interesting contributions detailed novel utilization of characterization techniques for studying a variety of materials. In particular, microscopy studies were described for each of the materials classes covered at the meeting.

The symposium was well attended throughout its four days. Many international researchers also participated in the meeting as both presenters and active attenders.

\section{Long-Wavelength Semiconductor Devices, Materials, and Processes (Symposium T)}

MRS Symposium Proceedings, Vol. 216 Organizers: Avishay Katz (ATET Bell Laboratories), Robert M. Biefeld (Sandia National Lab- omatories), R.J. Malik (ATET Bell Laboratories), Robert L. Gunshor (Pundue University).

Support: Aixtron; Blake Industries, Inc.; EPI Systems Div.-Chorus Corporation; Hughes Aircraft Company; MR Semicon Inc.; PerkinElmer Corponation; Sumitomo Electric Inc.

More than 120 papers were presented during this international symposium, by representatives of more than eight countries. This symposium focused entirely on the II-VI and III-V materials, processing, and devices. The high level of interest in this symposium forced the organizers to reject excellent papers that did not fit this year's theme. Moreover, the level of interest in the symposium was reflected, as well, in the high attendance, which exceeded 300 at its peak. The three-day symposium featured seven oral presentation sessions and an evening poster session. Excellent presentations were given by the keynote speaker R. Reynolds, and the invited speakers.

This symposium provided an appropriate forum for the enthusiastic audience and speakers to discuss the recent advances and processes associated with MgCdTe growth, devices and processes, narrow-gap IV-VI and III-V materials, and III-V long-wavelength materials, processing, and photonic devices.

\section{Materials Jynthesis Based on} Biological Processes (Symposium V) MRS Symposium Proceedings, Vol. 218 Organizers: Mark Alper (Center for Advanced Materials, Lawrence Berkeley Laboratory), Peter C. Rieke (Battelle Pacific Northwest Labomtory), Richand Frankel (Califormia Polytechnic State University), Paul D. Calvert (University of Arizona), David A. Tirrell (University of Massachusetts).

Support: Lawrence Berkeley Labomtory.

A great deal changed during the year since the first MRS symposium on this topic.

The first two sessions focused on synthesis of and by proteins. It is now clear that proteins can be modified to function at high temperatures and in organic solvents and that we are seeing progress toward the design of new "artificial" proteins for specific purposes. That biology has specialized on a single set of catalytic macromolecules may be telling us that these systems are versatile enough to carry out any chemical process we choose.

The next session centered on cells as factories to produce polymers and inorganic particles with potential application. The products include magnetic iron oxide particles, polyhydroxybutyrate (a filmforming polyester) iron sulfides, and 
cadmium sulfide. It is now clear that organisms can be persuaded to produce a wide range of particles if they are fed the right precursors. This led to a session on devices based on biological electronic or optical receptors.

The final sessions dealt with biomineralization and structural biopolymers. One area which has clearly made much progress since last year is the mineralization of collagen in vitro and of cell cultures. We are almost in a position to grow bone in a test tube. The fact that we can do it does not mean that we understand it yet, but it helps. This work will clearly affect the technology of bone implants.

Among the aims of this biological approach to materials are to (1) displace chemical catalysts with artificial enzymes, (2) grow ceramic particles and bulk plastics by fermentation, and (3) construct a new range of machines designed and built like living systems. These goals are not yet close, but real applications will clearly be among us soon.

\section{Scaling in Disordered Materials (Symposium W) \\ MRS Extended Abstract, Vol. EA-25}

Organizers: James $P$. Stokes (Exxon Research and Engineering Company), Mark $O$. Robbins (Johns Hopkins University), Tom A. Witten (University of Chicago).

Support: Office of Naval Research; Exxon Corporation; IBM-T.J. Watson Research Center; Schlumberger-Doll Research Center.

This year's symposium continued the trend of recent fractals symposia by broadening the scope. Our aim was to highlight new scaling phenomena and new ways of understanding them. Contributing to this end were 21 invited papers along with 43 contributed talks and 34 posters on subjects ranging from fractal growth to sandpiles and earthquakes.

The symposium started off with updates on recent work concerning fractal growth processes and multifractal analysis of complex structures. Next a joint session with Symposium I, Mechanical Properties of Porous Materials and Cellular Materials, covered scaling theories of fracture, and the morphology of cracks and fracture surfaces.

The next two sessions produced lively discussions on self-organized critical phenomena and scaling of disorderly dynamics. An effort was made to link ongoing work on dynamical critical phenomena in charge-density wave materials and fluid invasion to more recent work on self-organized critical phenomena in sand- piles, earthquakes, and magnetic domain walls.

The evening poster session was well attended as usual. The subjects ranged from multifractal analysis of random structures to scaling of dynamical processes in complex fluids and complemented well the topics covered in the oral sessions.

The third day of the symposium covered recent theoretical and experimental advances in the field of complex fluids. Topics included scaling properties of polymers at interfaces, in the melt, and in solution, along with scaling behavior of particles in suspension. The afternoon session explored dynamic and spatial scaling in turbulence and the technologically important scaling properties of porous media.

The symposium concluded with a stimulating session on the excitations of fractals. Different structural and dynamic probes were used to characterize vibrational properties of weakly connected composites and model fractal structures.

\section{Frontiers of Materials Research (Symposium X)}

Organizers: Rustum Roy (Pennsylvania State University).

Jointly sponsored by: U.S. Materials Education Council.

Symposium $X$ provides a unique vehicle to promote the interdisciplinary and integrative nature of MRS meetings. Each day, two invited tutorial reviews for the nonspecialist (in the topics covered at the meeting) are provided.

This year attendees (frequently more than 200) heard presentations by leaders in their fields, e.g., Paul Hagenmuller (Univ. of Bordeaux) spoke on nonstoichiometry in oxides and A.L. Greer (Univ. of Cambridge) spoke on metallic glasses. In a departure from the customary subject matter, Rustum Roy (Pennslyvania State Univ.) discussed proposed fundamental changes in K-12 science education and how materials researchers can be involved. This year also featured presentations by the first MRS Medal awardees, who described their research honored by the Society. They were Arthur J. Freeman, who talked about his work with manmade magnetic materials, and Duward F. Shriver, who described his research on polymer-based solid electrolyte materials. Both Freeman and Shriver hold position with Northwestern University.

\section{Nanostructures: Fabrication and Physics (Symposium Y) \\ MRS Extended Abstract, Vol. EA-26}

Organizers: T.P. Smith III (IBM T.J. Watson Research Center), Steven D. Berger (ATET Bell Laboratories), Dieter Kern (IBM T.J. Watson Research Center), Harold Craighead (Comell University).

Support: IBM Corpomtion; JEOL USA, Inc.

Recent advances in nanostructure fabrication and ultra-submicron lithography have fostered an explosive growth in lowdimensional materials, structures and physics.

As the field of nanostructures has grown, several key issues have emerged. Control and reduction of damage and extrinsic defects is crucial to fabricating nanometer-scale structures and devices with interesting properties. Key developments in this area included processing with focused ion beams, ion implantation, integrated processing, and selective growth techniques. While it is possible to pattern structures as small as a few nanometers, problems related to passivation and damage remain. The ultimate limits of lithography and pattern replication are two questions that are still unresolved. Several papers discussed novel lithographic techniques and applications. The use of a scanning tunneling microscope to position atoms provides at least one answer, and several talks on fabrication and characterization overviewed the use of scanning tunneling microscopy.

An overriding concern for much in this work is the question of applications. This symposium had sessions on optoelectronic, electronic, magnetic, and analytical exploitation of nanostructures. The potential for incorporating nanostructures in photonic devices was reviewed by Kerry Vahala and addressed in several papers. Some novel device concepts, such as the electron-diffraction devices described by Kazuhito Furuya, have emerged and are being investigated. While many of these devices are more suitable for basic research than commercial use, tremendous progress is being made.

The theoretical understanding of nanostructures continues to grow. Questions concerning coherence, ballistic transport and many-body effects still remain. The study of these fundamental issues and the complementary experimental work continue to yield new and intriguing results. New work on one-dimensional superlattices, coupled quantum dots, lateral resonant tunneling, and two-dimensional point contacts were all presented. The push to separate the ballistic transport effects from scattering and geometrical effects remains an important issue and a number of papers focused on this topic. 
Place your order now (if you haven't already!) for proceedings from the 1990 MRS Fall Meeting in Boston. You'll receive your books as soon as they are published. Contact the Materials Research Society, 9800 McKnight Road, Pittsburgh, PA 15237 U.S.A.; telephone (412) 367-3012 or 367-3036; fax (412) 367-4373.* Listed below are post-publication prices. If you order by March 1, 1991, you are entitled to a pre-publication discount. Call MRS for prices and to place your order (412) 367-3012; FAX (412) 367-4373.

\author{
Surface Chemistry and Beam-Solid \\ Interactions \\ Editors: H. Atwater, F.A. Houle, D. Lowndes \\ ISBN: 1.55899-093-3 Code: 201B \\ $\$ 39.00$ MRS Members \\ $\$ 44.00$ US List $\$ 52.00$ Foreign \\ Evolution of Thin Film and Surface \\ Microstructure \\ Editors: C.V. Thompson, J.Y. Tsao, D.J. Srolovitz \\ ISBN: 1.55899-094.1 Code: 202B \\ $\$ 57.00$ MRS Members \\ $\$ 64.00$ US List $\$ 71.00$ Foreign
}

Electronic Packaging Materials Science V

Editors: E.D. Lillie, R.J. Jaccodine, P. Ho,

K. Jackson

ISBN: 1.55899.095.X Code: 203B

$\$ 35.00$ MRS Members

$\$ 42.00$ US List $\$ 47.00$ Foreign

Chemical Perspectives of Microelectronic

Materials II

Editors: L.H. Dubois, L.V. Interrante, M.E. Gross,

K.F. Jensen

ISBN: 1-55899-096-8 Code: 204B

$\$ 42.00$ MRS Members

$\$ 49.00$ US List $\$ 56.00$ Foreign

Kinetics of Phase Transformations

Editors: M.O. Thompson, M.J. Aziz,

G.B. Stephenson, D. Cherns

ISBN: 1-55899-097-6 Code: 205B

$\$ 40.00$ MRS Members

$\$ 47.00$ US List $\$ 54.00$ Foreign

Clusters and Cluster-Assembled Materials

Editors: R.S. Averback, D.L. Nelson, J. Bernholc

ISBN: 1.55899.098-4 Code: 206B

$\$ 40.00$ MRS Members

$\$ 47.00$ US List $\$ 54.00$ Foreign

Mechanical Properties of Porous and Cellular Materials

Editors: L.J. Gibson, D. Green, K. Sieradzki

ISBN: 1-55899-099.2 Code: 207B

$\$ 30.00$ MRS Members

$\$ 37.00$ US List $\$ 44.00$ Foreign

Advances in Surface and Thin Film Diffraction

Editors: P.I. Cohen, D.J. Eaglesham, T.C. Huang

ISBN: 1.55899-100-X Code: 208B

$\$ 35.00$ MRS Members

$\$ 40.00$ US List $\$ 45.00$ Foreign

\section{Defects in Materials \\ Editors: P.D. Bristowe, J.E. Epperson, \\ J.E. Griffith, Z. Liliental-Weber \\ ISBN: 1.55899-101-8 Code: 209B \\ $\$ 50.00$ MRS Members \\ $\$ 57.00$ US List $\$ 64.00$ Foreign}

Solid State lonics II

Editors: G.-A. Nazri, R.A. Huggins, D.F. Shriver,

M. Balkanski

ISBN: 1-55899-102-6 Code: 210B

$\$ 40.00$ MRS Members

$\$ 47.00$ US List $\$ 54.00$ Foreign

Fiber-Reinforced Cementitious Materials

Editors: S. Mindess, J.P. Skalny

ISBN: 1.55899.103-4 Code: 211B

$\$ 35.00$ MRS Members

$\$ 42.00$ US List $\$ 49.00$ Foreign

Scientific Basis for Nuclear Waste

Management XIV

Editors: T. Abrajano, Jr., L.H. Johnson

ISBN: 1.55899-104-2 Code: 212B

$\$ 50.00$ MRS Members

$\$ 57.00$ US List $\$ 64.00$ Foreign

High Temperature Ordered Intermetallic

Alloys IV

Editors: L. Johnson, D.P. Pope, J.O. Stiegler

ISBN: 1-55899-105-0 Code: $213 \mathrm{~B}$

$\$ 48.00$ MRS Members

$\$ 55.00$ US List $\$ 62.00$ Foreign

Optical and Electrical Properties of Polymers Editors: J.A. Emerson, J.M. Torkelson

ISBN: 1-55899-106.9 Code: $214 \mathrm{~B}$

$\$ 33.00$ MRS Members

$\$ 40.00$ US List $\$ 47.00$ Foreign

Structure, Relaxation and Physical Aging of Glassy Polymers

Editors: R.J. Roe, J.M. O'Reilly, J. Torkelson

ISBN: 1-55899-107.7 Code: 215B

$\$ 33.00$ MRS Members

$\$ 38.00$ US List $\$ 45.00$ Foreign

Long-Wavelength Semiconductor Devices, Materials and Processes

Editors: A. Katz, R.M. Biefeld, R.J. Malik,

R.L. Gunshor

ISBN: 1-55899-108-5 Code: $216 \mathrm{~B}$

$\$ 38.00$ MRS Members

$\$ 45.00$ US List $\$ 52.00$ Foreign
Advanced Tomographic Imaging Methods for the Analysis of Materials

Editors: J.L. Ackerman, W.A. Ellingson

ISBN: 1.55899.109.3 Code: 217B

$\$ 37.00$ MRS Members

$\$ 44.00$ US List $\$ 51.00$ Foreign

Materials Synthesis Based on Biological

Processes

Editors: M. Alper, P.C. Rieke, R. Frankel,

P.D. Calvert, D.A. Tirrell

ISBN: 1-55899-110-7 Code: $218 \mathrm{~B}$

$\$ 38.00$ MRS Members

$\$ 45.00$ US List $\$ 52.00$ Foreign

EXTENDED ABSTRACTS (Available Now)

Electronic, Optical and Device Properties of Layered Structures

Editors: J. Hayes, M.S. Hybertsen, E.R. Weber $\$ 18.00$ MRS Members Code EA.21B

$\$ 20.00$ US List $\$ 22.00$ Foreign

Dynamics in Small Confining Systems

Editors: J.M. Drake, R. Kopelman, J. Klafter

$\$ 18.00$ MRS Members Code EA-22B

$\$ 20.00$ US List $\$ 22.00$ Foreign

Covalent Ceramics

Editors: G.S. Fischman, T. Aselage,

R.M. Spriggs

$\$ 18.00$ MRS Members Code EA.23B

$\$ 20.00$ US List $\$ 22.00$ Foreign

Synthesis and Properties of New Catalysts:

Utilization of Novel Materials Components and

Synthetic Techniques

Editors: E.W. Córcoran, Jr., M.J. Ledoux,

J.R. Knox

$\$ 18.00$ MRS Members Code EA-24B

$\$ 20.00$ US List $\$ 22.00$ Foreign

Scaling in Disordered Materials

Editors: J.P. Stokes, M.O. Robbins, T.A. Witten

$\$ 18.00$ MRS Members Code EA.25B

$\$ 20.00$ US List $\$ 22.00$ Foreign

Nanostructures: Fabrication and Physics

Editors: T.P. Smith III, S.D. Berger, D. Kern,

H. Craighead

$\$ 18.00$ MRS Members Code EA.26B

$\$ 20.00$ US List $\$ 22.00$ Foreign 


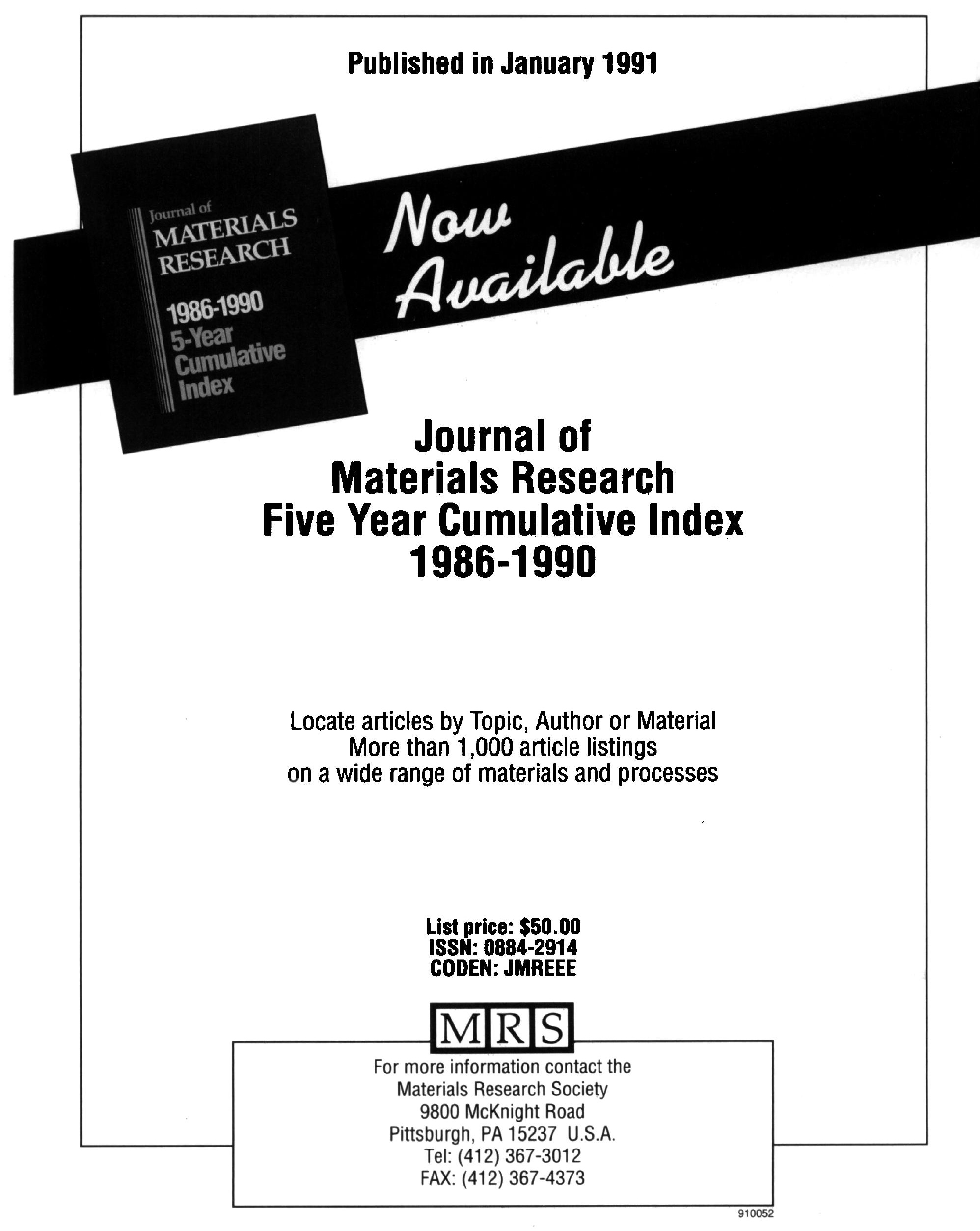

